\title{
KARAKTER INDIS KAWASAN SAGAN LAMA YOGYAKARTA
}

\author{
Hatta Musthafa Adham Putra. \\ Staf Pengajar Program Studi Arsitektur, Jurusan Desain \\ Politeknik Negeri Samarinda \\ E-mail: hattamusthafa@gmail.com
}

\begin{abstract}
Old Sagan area is an area in Yogyakarta, which still preserves its architectural and region. Architecturally, this area is a building of residential-style that has a form of Indisch, colonial influence Dutch inherent in all the land until the construction of the roof of the House. By region, the region has the character of the old settlement of Sagan with ordered plots of land, vegetation and the placement of a planned land not aroused.

The existence of Old Sagan located in the middle of the city became an important part in the development of this important region. Various influences lifestyles and needs of the people began to affect the region, especially the commercial side. Character of the area began to undergo transformation because of the influence of pressure from the surrounding area is growing rapidly with commercialization.
\end{abstract}

Keywords : character, housing, indisch

\begin{abstract}
ABSTRAK
Kawasan Sagan Lama adalah salah satu kawasan di Yogyakarta yang masih mempertahankan ciri khasnya baik secara arsitektural maupun kawasan. Secara arsitektural, kawasan ini adalah permukiman yang memiliki bentuk bangunan bergaya indisch, pengaruh kolonial belanda melekat pada keseluruhan bangunan mulai dari lahan hingga atap rumah. Secara kawasan, kawasan Sagan Lama memiliki karakter berupa permukiman dengan persil lahan yang rapi, penempatan vegetasi serta lahan tak terbangun yang terencana.

Keberadaan kampung Sagan yang terletak di tengah kota menjadi bagian penting yang patut diperhatikan dalam perkembangan kawasan. Berbagai pengaruh gaya hidup dan kebutuhan manusia mulai mempengaruhi kawasan, terutama sisi komersial. Karakter kawasan mulai mengalami transformasi akibat pengaruh desakan dari kawasan sekitarnya yang tumbuh pesat dengan aroma komersialisasi.
\end{abstract}

Kata kunci : karakter, Permukiman, indisch

\section{A. PENDAHULUAN}

Kawasan Sagan Lama merupakan kampung yang ada di Yogyakarta yang masih mempertahankan ciri khasnya baik secara arsitektural maupun kawasan. Secara arsitektural, kawasan ini memiliki bentuk bangunan bergaya indisch, pengaruh kolonial belanda melekat pada keseluruhan bangunan mulai dari lahan hingga atap rumah. Secara kawasan, Sagan Lama memiliki karakter berupa perumahan dengan persil lahan yang rapi, penempatan vegetasi serta lahan tak terbangun yang terencana. 
Hatta Musthafa Adham Putra, Karakter Indis Kawasan Sagan Lama Yogyakarta

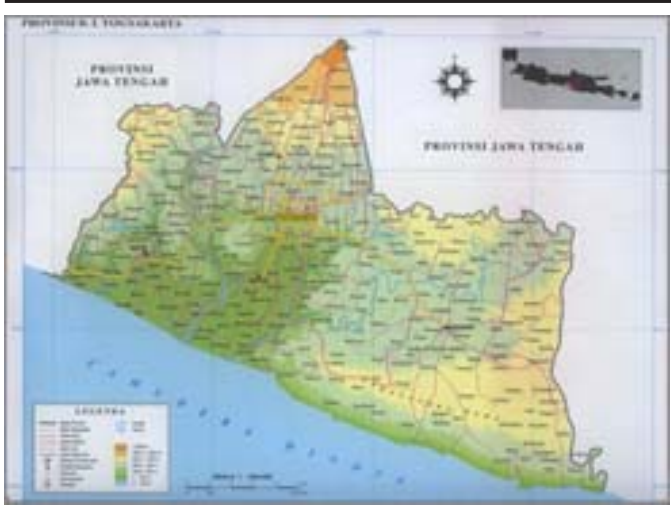

Gambar 1

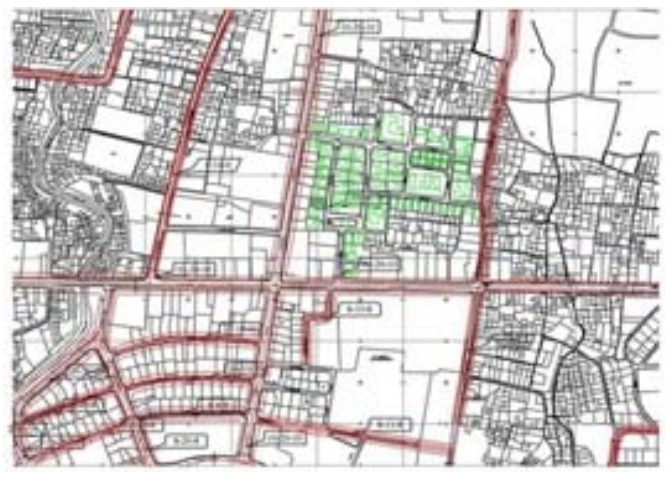

Gambar 2

Gambar 1-2. Peta Lokasi Kampung Sagan Yogyakarta

Sumber : Bappeda Kota Yogyakarta, 2001

Keberadaan kawasan Sagan yang terletak di tengah kota menjadi bagian penting yang patut diperhatikan dalam perkembangan kawasan. Berbagai pengaruh gaya hidup dan kebutuhan manusia mulai mempengaruhi kawasan, terutama sisi komersial. Beberapa bangunan mulai mengalami perubahan fungsi, struktur persil lahan, hingga gaya arsitektural bangunan. Bangunan yang awalnya hanya berupa rumah tinggal berubah menjadi warung makan, toko, apotik, dan fungsi lain yang secara komersial menjadi terbuka untuk umum. Dampak utama dari perubahan fungsi terebut adalah adanya pergeseran morfologi dan spasial bangunan di kawasan Sagan. Ciri khas bangunan maupun fungsi bangunan mulai mengalami transformasi akibat pengaruh desakan dari kawasan sekitarnya yang tumbuh pesat dengan aroma komersialisasi.
Kawasan Sagan Lama adalah salah satu kawasan di Yogyakarta yang di dalamnya terdapat bangunan cagar budaya dalam bentuk bangunan Indis peninggalan kolonial Belanda. Pasal 1 UU No. 5/1992 menyebutkan bahwa Bangunan Cagar Budaya adalah segala bentuk bangunan yang berupa kesatuan atau kelompok, berumur 50 tahun atau lebih, atau mewakili gaya bangunan yang berumur 50 tahun atau lebih, serta dianggap mempunyai nilai penting bagi sejarah, ilmu pengetahuan dan kebudayaan.

Yogyakarta memiliki 407 bangunan warisan budaya yang terdaftar pada 2009. dari 407 bangunan tersebut, 13 diantaranya berada di kawasan Sagan ${ }^{2}$. Bangunan ini telah terdaftar setelah melalui tahapan survey hingga penetapan oleh dinas Kebudayaan Kota Yogyakarta. Kawasan cagar budaya penting dipelihara karena aspek Budaya, Ekonomi dan Pendidikan.

\section{B. Gambaran Lokasi Kampung Sagan}

Perumahan kolonial di Sagan yang dipilih sebagai lokasi penelitian adalah sebuah perumahan yang dibangun oleh Belanda di bagian Utara Kota Yogyakarta yang berbatasan langsung dengan Kabupaten Sleman. Lokasi penelitian kini termasuk kedalam wilayah RW 12, Kelurahan Terban, Kecamatan Gondokusuman, Yogyakarta.

Luas wilayah keseluruhan RW 12 menurut monografi Kelurahan Terban tahun 2005 mencapai 12,8 hektar dengan jumlah KK mencapai 235 KK. Adapun batas-batas wilayah RW 12 adalah :

- Bagian Utara:

Jl. Kartini atau yang dahulu dikenal dengan nama Jl. Sagan Lor.

- Bagian Timur:

Jl. Prof. Herman Yohannes atau dikenal dengan nama Jl. Reksonegaran.

- Bagian Barat:

Rumah-rumah tinggal yang ada di sebelah Timur Jl. Cik Di Tiro atau yang dahulu dikenal dengan nama Dr. Yap Boulevard. 


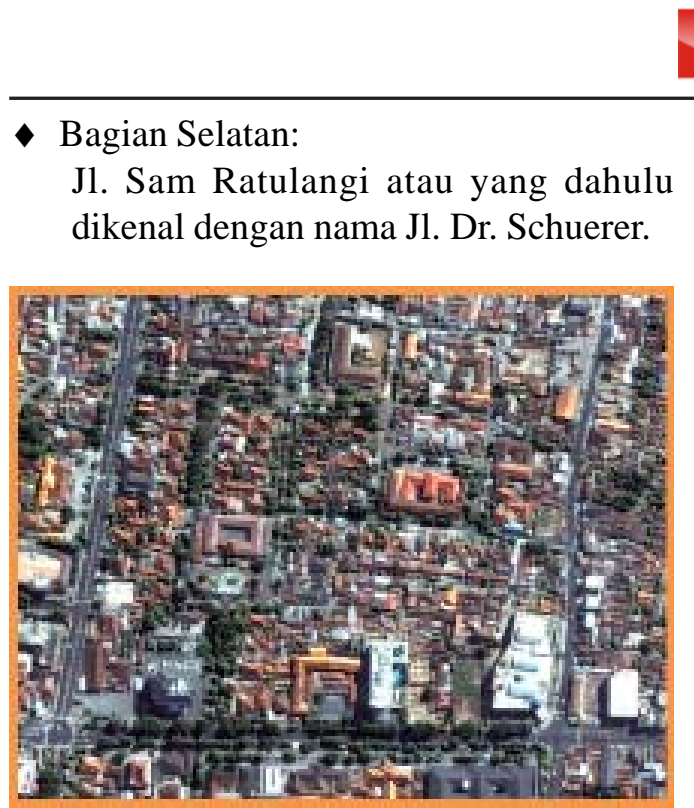

Gambar 3. Foto udara kawasan Kampung Sagan

Sumber : Google earth 2006

Nama Sagan Lama dan Sagan Baru merupakan penyebutan yang diberikan oleh masyarakat sekitar untuk membedakan dua buah perumahan yang dibangun pada waktu berbeda dalam satu kampung yang sama yaitu Kampung Sagan. Sagan Lama merupakan perumahan kolonial yang didirikan oleh Belanda pada sekitar tahun 1930-an sebagai kawasan rumah dinas amteenar Belanda.

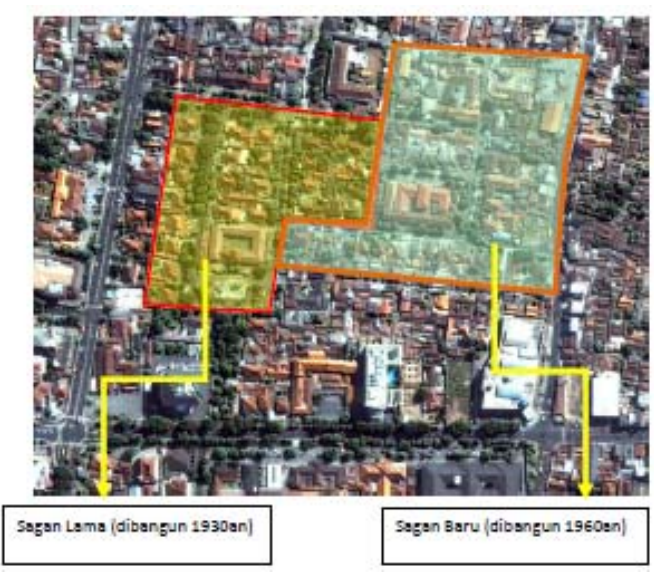

Gambar 4 Pembagian area Kampung Sagan Lama dan Sagan Baru Sumber : google earth 2006, analisa penulis
Vol. 2, No. 1, Oktober 2014

Kampung Sagan Lama sebagai satu dari beberapa kawasan peninggalan Belanda di Yogyakarta, memiliki blok kawasan yang tertata rapi dan arsitektur Indisch yang kental. Di samping itu, setting karakter kawasan sangat unik dengan persil, ruang jalan, vegetasi yang sangat tertata serta berlokasi strategis di lingkup kota Yogyakarta. Hal ini disebabkan karena kawasan Sagan Lama merupakan permukiman yang benar-benar dibangun tertata rapi sebagaimana layaknya perumahan terencana saat ini.

\section{PEMBAHASAN \\ C.1 Pola Massa Bangunan dalam Kawasan}

Bangunan di Kampung Sagan Lama terdiri dari bangunan satu dan dua lantai. Pada tahun 2010 terdapat satu bangunan 4 lantai yaitu Hotel Sagan. Bangunan tersusun mengikuti pola jalan seperti halnya sebuah permukiman dengan format perumahan.

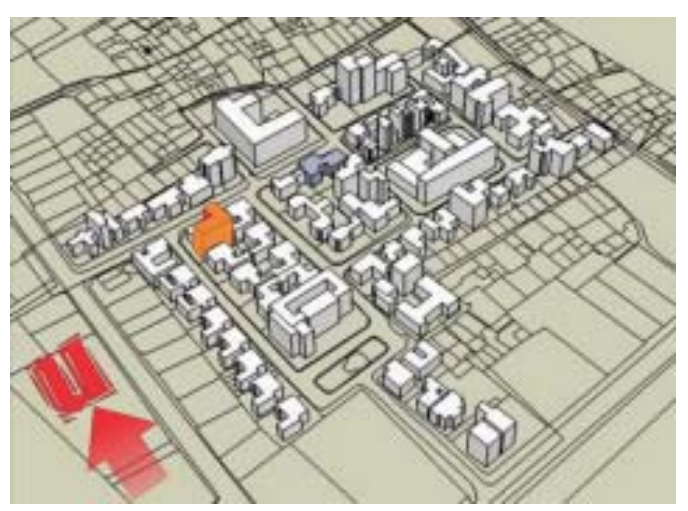

Gambar 5. Pola massa kawasan Kampung Sagan Lama

Sumber : Analisa Penulis

Selain pola massa yang tertata, beberapa bangunan masih memperlihatkan bentuk massa aslinya. Hal ini terlihat dari jarak antar bangunan maupun jarak bangunan dengan jalan. Dari pola massa ini juga memperlihatkan suatu pola grid sebagai implementasi dari permukiman yang terencana. 
Hatta Musthafa Adham Putra, Karakter Indis Kawasan Sagan Lama Yogyakarta

\section{C.2 Pola Persil Kawasan}

Layaknya sebuah perumahan terencana yang dibangun pada jaman Kolonial Belanda, Kampung Sagan Lama memiliki pola persil yang tertata. Perencanaan kawasan ketika sebelum pembangunan serta diperkuat oleh aturan bangunan cagar budaya, menyebabkan kawasan ini terjaga seperti kondisi aslinya.

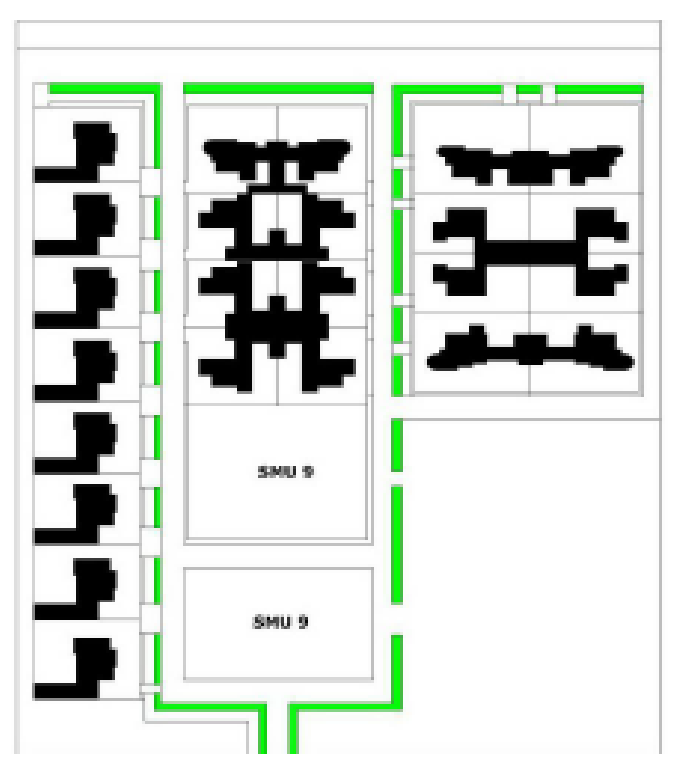

Gambar 6. Pola persil kawasan Kampung Sagan Lama

Sumber : Analisa Penulis

Persil kawasan membagi area permukiman menjadi simetris. Namun terdapat beberapa persil yang lebih lebar dibandingkan dengan persil lainnya, yaitu di area sudut. Pola persil ini masih bertahan hingga sekarang, meskipun fungsi beberapa bangunan telah berubah dan terdapat penambahan bangunan di beberapa sisi.

\section{C.3 Setback Kawasan}

Kawasan Sagan Lama memiliki persil yang terpola, demikian pula setback kawasan. Meskipun di beberapa tempat terdapat beberapa persil dengan sempadan yang berbeda, namun secara keseluruhan memperlihatkan pola sempadan yang tertata rapi, dengan jarak yang sama terhadap jalan. Perbedaan setback muncul akibat adanya penambahan bangunan baru selain bangunan utama.

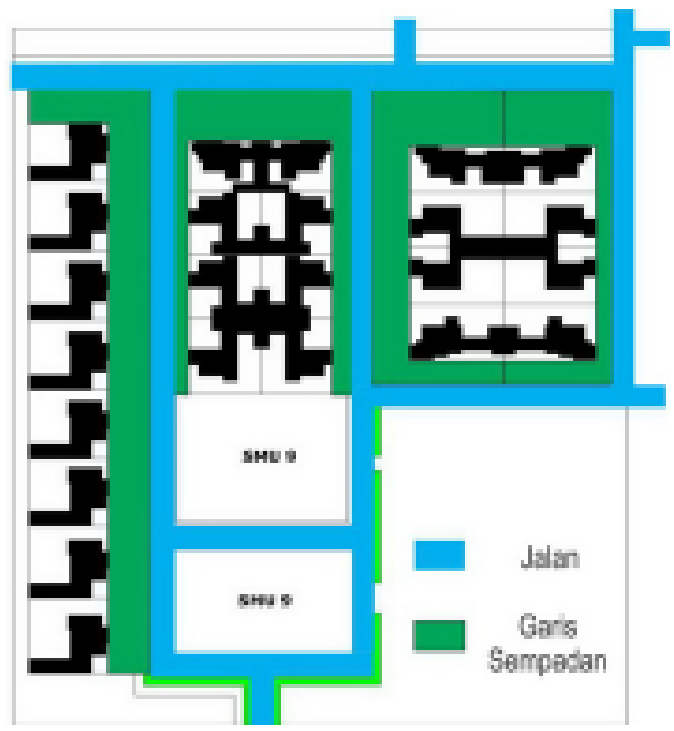

Gambar 7. Setback kawasan Kampung Sagan Lama

Sumber : Analisa Penulis

\section{C.4 Elemen Sky Line Pembentuk Karakter Kawasan Sagan Lama}

Berdasarkan wawancara dengan penduduk setempat, diketahui bahwa hanya ada satu bangunan yang masih mendekati asli, dalam arti minim perubahan. Rumah tersebut adalah Rumah tinggal di Jl. Dewi Sartika no. 5 yang memiliki luas lahan kurang lebih $1000 \mathrm{~m}^{2}$ ini merupakan kediaman dari keluarga Ibu Tri Sedjati Kolopaking salah seorang dosen di Fakultas Sastra Universitas Teknologi Yogyakarta.

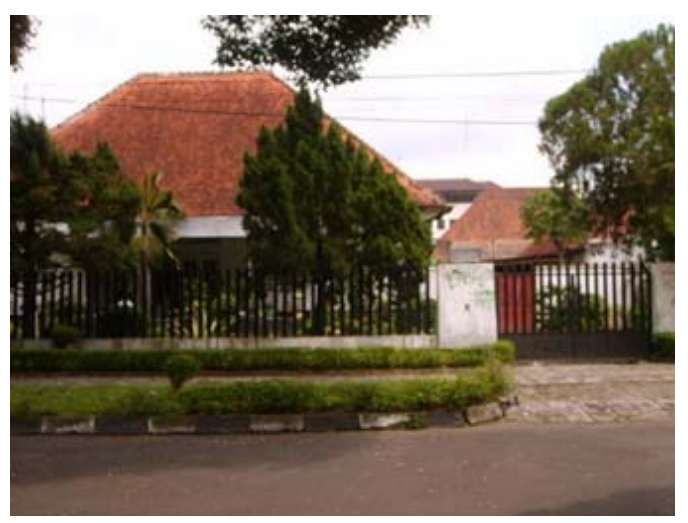

Gambar 8. Rumah asli di kawasan kampung Sagan Lama

Sumber : Dokumentasi Penulis, 2010 


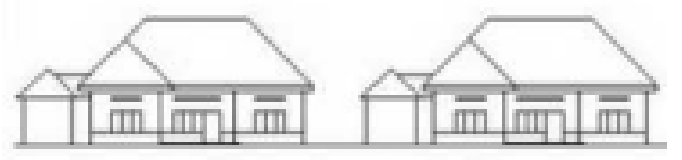

Gambar 9. Sketsa Rumah asli di kawasan kampong Sagan Lama

Sumber : Analisa Penulis

Sky Line terbentuk oleh perpaduan garis atap dari tiap bangunan. Perpaduan ritme dan geometri bentuk tersebut menciptakan pola yang akan menjadi sky line.

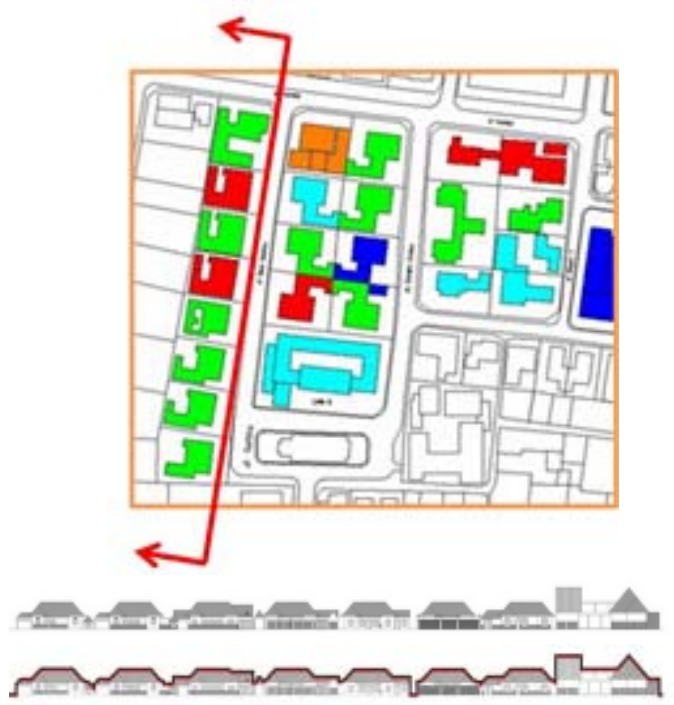

Gambar 10. Sky line penggal Jl. Dewi Sartika, kawasan Kampung Sagan Lama Sumber : Analisa penulis

\section{Kesimpulan dan Saran}

Kawasan Sagan Lama adalah salah satu kawasan di Yogyakarta yang masih mempertahankan karakter fisik berupa permukiman dengan persil lahan yang rapi, penempatan vegetasi serta lahan tak terbangun yang terencana. Keberadaan Sagan Lama ini berdekatan dengan kawasan Kotabaru Yogyakarta yang mencirikan kawasan indis dengan ruang hijau yang memadai

Kawasan Sagan Lama masih memiliki karakter kuat yang dapat dirasakan. Namun jika tidak dilakukan pengawasan dan pemberlakuan regulasi, dikhawatirkan karakter tersebut akan hilang perlahan. Untuk itu, secara umum perlu adanya regulasi yang mengatur perubahan kawasan dalam rangka mempertahankan karakter kawasan Sagan Lama Yogyakarta ini.

a. diharapkan peran serta pemerintah melalui dinas kebudayaan dalam rangka menjaga kelestarian kawasan Sagan Lama sebagai kawasan budaya dan memiliki karakter khas Indis.

b. perlu adanya regulasi yang mengatur secara khusus tentang bangunan dan massa dalam kawasan. Keseragaman tinggi bangunan, bentukan massa serta gaya bangunan merupakan factor penting dalam menjaga karakter kawasan Sagan Lama.

c. Untuk daerah kawasan lain di Indonesia, perlu adanya pendataan kawasan yang memiliki nilai sejarah tinggi, serta upaya pemerintah untuk mempertahankan bangunan dalam kawasan tersebut sehingga menjadi aset sejarah arsitektural daerah yang bermanfaat. 


\section{DAFTAR PUSTAKA}

Buku Informasi Museum Bangunan-Bangunan Indis. 2001. Departemen Pendidikan Nasional

Dinas Pariwisata Seni dan Budaya, 2007. Toponim Kota Yogyakarta.

Laporan Pendataan Kawasan Kotabaru. 2007. Balai Pelestarian Peninggalan Purbakala Moughtin, Cliff. Urban Design, Street and Square. 2003. Architectural Press, Burlington Shirvani, Hamid, 1985. The Urban Design and Process. Van Nostrand Reinhold. New York.

Suaka Peninggalan Sejarah dan Purbakala DIY. 2007. Hasil Pendataan Bangunan Indis di Kawasan Bintaran Yogyakarta. Departemen Pendidikan dan Kebudayaan

Trancik, Roger. 1986. Finding Lost Space : Theories of Urban Design, Van Nostrand Reinhold. New York.

\section{WEBTOGRAFI}

architect-news.com

Elantowow.wordpress.com

Purbakalayogya.com

wikipedia.com

Yogyakarta.kemenag.go.id 